\title{
How can we reverse bleeding in patients on direct oral anticoagulants?
}

\author{
Mark Crowther ${ }^{1}$, Adam Cuker ${ }^{2}$ \\ 'McMaster University, Hamilton, Ontario, Canada \\ ${ }^{2}$ University of Pennsylvania, Philadelphia, PA, United States
}

\begin{abstract}
A bstract
The direct oral anticoagulants (DOACs), or non-vitamin K antagonist oral anticoagulants (NOACs), including dabigatran, which inhibits thrombin, as well as rivaroxaban, apixaban, edoxaban, and betrixaban, which inhibit coagulation factor $\mathrm{Xa}$, are associated with similar or lower risk of bleeding compared with warfarin. The need for reversal of their anticoagulant effect may occur in patients with life-threatening bleeding or those requiring urgent surgery. Currently, the only specific reversal agent for dabigatran, idarucizumab, is widely available, while andexanet alfa, which reverses factor Xa inhibitors, was approved in the United States in May 2018. Ciraparantag, which has been designed to reverse all DOACs and other anticoagulants, is being investigated in clinical trials. In the absence of licensed reversal agents for the oral factor Xa inhibitors, prothrombin complex concentrates are suggested in patients with life-threatening bleeding. Vitamin $\mathrm{K}$ and fresh frozen plasma should not be used to reverse DOACs. This review presents the current evidence regarding bleeding risk on DOACs and the reversal strategies to provide guidance on the management of patients treated with DOACs, who experience serious bleeding.
\end{abstract}

Key words: bleeding, non-vitamin $\mathrm{K}$ antagonist oral anticoagulants, reversal agents

Kardiol Pol 2019; 77, 1: 3-11

\section{INTRODUCTION}

Non-vitamin $\mathrm{K}$ antagonist oral anticoagulants (NOACs) or target-specific oral anticoagulants (TSOACs), which directly inhibit coagulation factor (F) Xa (rivaroxaban, apixaban, edoxaban, and betrixaban) or thrombin (dabigatran), are increasingly used worldwide. The International Society on Thrombosis and Haemostasis has recommended using the term direct oral anticoagulants (DOACs), which will be used in the present review [1]. The DOACs have common characteristics: (i) they are all oral; (ii) they all have rapid absorption and their profile is very similar to that of low-molecular-weight heparin in terms of their pharmacokinetics; (iii) compared to other oral anticoagulants, particularly warfarin, they have remarkably short half-lives (about 12 h); (iv) they have no off-target toxicity. There is no increased risk of leukaemia, liver failure, or other adverse reactions, and any allergic reactions to the DOACs are caused by the dye used in the tablet or capsule, not by the compound itself.

The phase III trials evaluating the efficacy and safety of the DOACs in patients with nonvalvular atrial fibrillation (AF) for the prevention of stroke and systemic embolism [2-6] and the treatment and prevention of venous thromboembolism (VTE) [7-10] have demonstrated that DOACs have a favourable risk-benefit profile in comparison with a vitamin $\mathrm{K}$ antagonist (VKA), warfarin.

However, there are indications in which all physicians will continue to use warfarin for the foreseeable future, most notably in patients with mechanical heart valves and patients with "high-risk" antiphospholipid antibody syndrome [11].

\section{BLEEDING RISK IN PATIENTS ON DOACS}

There is compelling evidence that DOACs are as effective in reducing thromboembolic events as warfarin, but they are safer with respect to major and fatal bleeding, in particular intracranial haemorrhage $[12,13]$. All large clinical studies of DOACs were conducted without specific antidotes being available.

Clinical registries and large retrospective database studies, including a Food and Drug Administration (FDA) analysis of $>134,000$ Medicare patients with AF and Danish nation-wide analyses, demonstrate results consistent with those reported in randomised controlled trials (RCTs) [14-18].

Address for correspondence:

Mark Crowther, MD, MSc, FRCPC, FRSC, Chair, Department of Medicine, Leo Pharma Chair in Thromboembolism Research, Rm 4V32 McMaster University Medical Centre, Hamilton, Ontario, Canada, e-mail: crowthrm@mcmaster.ca

Received: 13.09.2018 Accepted: 13.09.2018 Available as AoP: 24.09.2018

Kardiologia Polska Copyright (C) Polish Cardiac Society 2019 
A systematic review by Chai-Adisaksopha et al. [19], which comprised 12 RCTs (VTE, $n=7$ and $A F, n=5$ ) involving 102,607 patients (Table 1), was the first meta-analysis to examine the impact of bleeding complications of DOACs compared with VKAs in patients with VTE or AF. Patients were treated for 1.6 to 2.0 years in most of the AF trials, while the duration of the VTE trials was between three to 12 months. The average age was from 70 to 73 years in the AF trials and 54 to 57 years in the VTE trials [19]. It has been confirmed that intracerebral bleeding, the most feared haemorrhagic adverse event in patients receiving oral anticoagulants, is reduced by $>50 \%$ while using the DOACs compared with warfarin. Intracranial bleeding represents $8.7 \%$ of all major bleeding episodes in VKA users and results in a $46 \%$ to $55 \%$ mortality rate $[20,21]$.

Patients with AF or VTE on DOACs have been found to have a lower risk of overall major bleeding (relative risk [RR] 0.72, number needed to treat [NNT] 156), fatal bleeding (RR 0.53, NNT 454), clinically relevant non-major bleeding (RR 0.78, NNT 99), and all bleeding (RR 0.76, NNT 18) [19]. Interestingly, Chai-Adisaksopha et al. [19] did not observe an increased risk of gastrointestinal (GI) bleeding (RR 0.94, 95\% confidence interval [Cl] 0.88-1.34; Table 1), in contrast to a few published systematic reviews in which DOACs were compared with standard care $[12,22]$. An increase in the risk of Gl bleeding was observed in the RCTs evaluating dabigatran and rivaroxaban in AF patients $[2,4]$. In the RE-LY trial dabigatran $150 \mathrm{mg}$ twice a day (but not dabigatran $110 \mathrm{mg}$ twice a day) increased the risk of major Gl bleeding compared with warfarin (RR 1.50, 95\% Cl 1.19-1.89) [2], whereas in the ROCKET-AF trial rivaroxaban $20 \mathrm{mg}$ once daily increased this risk by $1 \%$ ( $3.2 \%$ vs. $2.2 \%$ ) [4]. The mechanism underlying DOAC-associated GI bleeding is probably the presence of the active drugs in the Gl tract, which precipitates bleeding from vulnerable lesions [23]. The discrepancy of the findings of various systematic reviews might be explained by differences in the populations and the comparators used.

There is consensus that the best way to treat bleeding in a patient on an anticoagulant is to avoid having a bleed, and this can be achieved by using the medications with the lowest risk of bleeding.

Warfarin is known to have the highest risk of major bleeding; therefore, a DOAC should be used in many patients at high bleeding risk.

Similarly, a very common cause of avoidable bleeding is coincident use of acetylsalicylic acid (ASA) and a DOAC or warfarin. Concomitant administration of antiplatelet drugs and nonsteroidal anti-inflammatory drugs should be avoided when possible. Most patients who are on warfarin and ASA do not need ASA. In a patient who is receiving any form of oral anticoagulant and any form of antiplatelet agent, the most important thing in the prevention of bleeding is to consider whether they need to be on dual antithrombotic therapy, and to be confident in discontinuing one of the antithrombotic drugs if it is not indicated. The current European Society of Cardiology guidelines recommend that oral anticoagulation alone, not combination therapy with ASA or another antiplatelet agent, be administered in AF patients with stable coronary artery disease, who did not experience an acute coronary syndrome and/or coronary intervention in the previous 12 months [24, 25].

\section{SPECIFIC STRATEGIES TO REVERSE ANTICOAGULANT EFFECTS OF THE DOACS}

In decision-making regarding all clinical problems, good quality evidence is of particular value. Unfortunately, in the field of reversing anticoagulants, including DOACs, there is no level IA evidence, and there will probably never be such evidence.

\section{Idarucizumab}

Idarucizumab is a humanised monoclonal antibody fragment, which is a specific reversal agent for dabigatran. It binds with 350-times higher affinity than thrombin to free and thrombin-bound dabigatran within minutes of its administration [26]. This reaction is irreversible [27]. Idarucizumab is primarily eliminated renally [28, 29], and the drug exposure is increased in patients with impaired renal function, which is consistent with higher dabigatran concentrations in such patients. In phase I and II clinical trials, reversal of anticoagulant effects of dabigatran by idarucizumab in a dose-dependent manner has been convincingly demonstrated based on measurements of activated partial thromboplastin time (APTT), thrombin time (TT), diluted TT (dTT), ecarin clotting time, and activated clotting time (ACT) in healthy volunteers and in subjects with reduced creatinine clearance [28, 30, 31].

No effects on coagulation parameters were observed when idarucizumab was administered in subjects not taking dabigatran [28].

Idarucizumab was approved in the United States by the FDA in October 2015 and in Europe one month later. It has become the standard of care for the reversal of dabigatran when it is available [32-34].

The Reversal Effects of Idarucizumab on Active Dabigatran (RE-VERSE AD) study was a phase III, prospective cohort study designed to show the safety and efficacy of idarucizumab (administered as two consecutive rapid 2.5-g intravenous boluses) in dabigatran-treated patients who present with uncontrolled or life-threatening bleeding (group A) or nonbleeding patients who require emergent surgery or invasive procedure (group B) [35]. The primary outcome of the RE-VERSE AD study was maximum percentage reversal of the anticoagulant effect of dabigatran expressed using dTT and ecarin clotting time performed in a central laboratory. Results of the RE-VERSE AD study were published twice in the New England Journal of Medicine, i.e. an interim analysis of the 


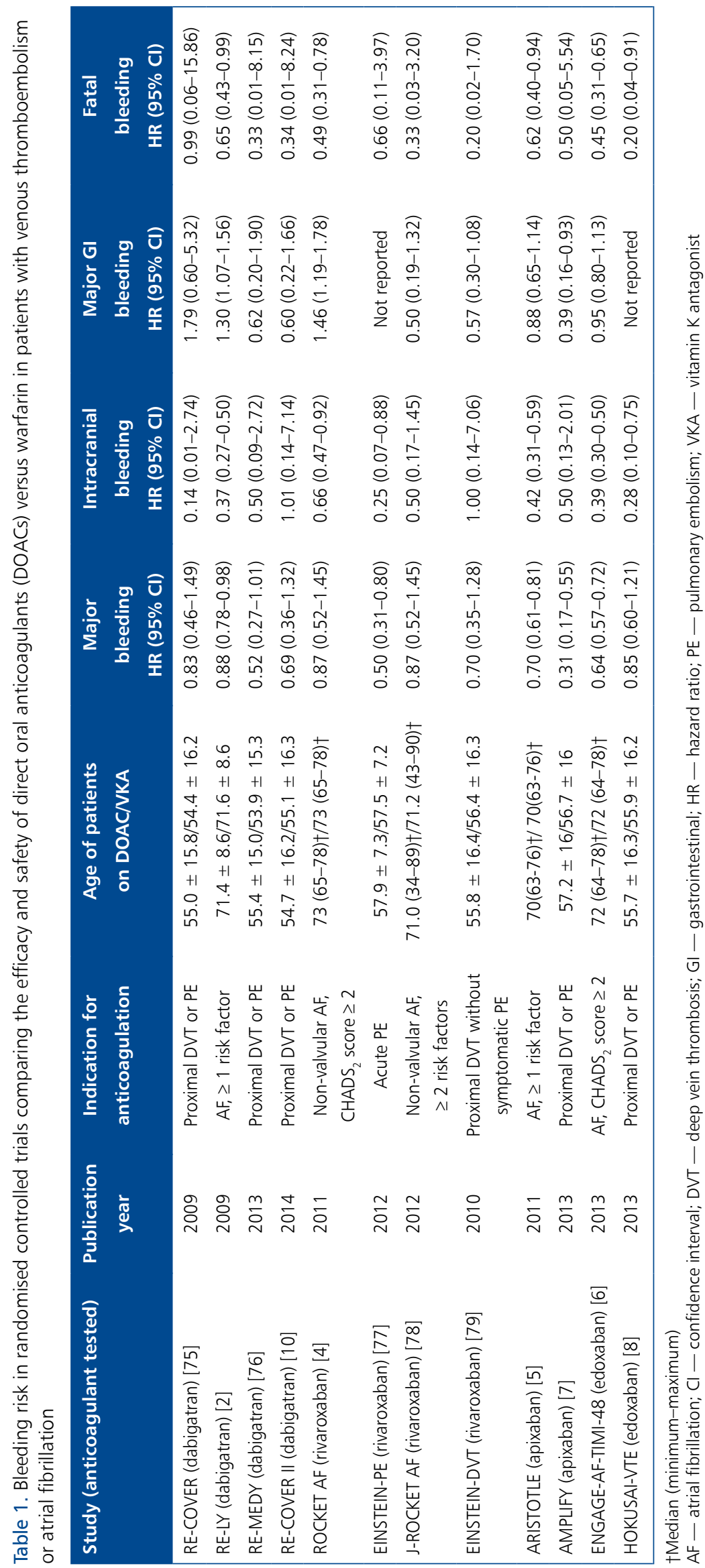


first 90 patients ( 51 with uncontrolled, life-threatening bleeding [group $\mathrm{A}$ ] and 39 undergoing urgent surgery or an invasive procedure [group B]) in 2015 [35] and the final analysis of 503 patients $(\mathrm{n}=301$ [group $\mathrm{A}$ ] and $\mathrm{n}=202$ [group B]) in 2017 [36].

Most participants (95.7\%) from 39 countries were treated with dabigatran to prevent AF-associated stroke. The median age of participants was 78 years. The efficacy analysis included 461 patients with prolonged dTT or elevated ecarin clotting time, and the median maximum percentage reversal was $100 \%$ within $4 \mathrm{~h}$ following idarucizumab administration. The median time to cessation of bleeding in bleeding patients was $2.5 \mathrm{~h}$. The median time to initiation of procedure in patients requiring surgery was $1.6 \mathrm{~h}$, and haemostasis was assessed as normal in $93.4 \%$ of the participants. The 30 -day mortality rate was $13.5 \%$ in group $A$ and $12.6 \%$ in group $B$, with most deaths occurring within five days after enrolment.

Of note, nine participants received an additional dose of idarucizumab due to recurrent bleeding or the need for a second urgent procedure, which was related to recurrent prolongation of clotting time due to redistribution of unbound dabigatran from the extravascular to the intravascular compartment.

The RE-VERSE AD study demonstrated the utility of idarucizumab in two groups of patients: those with life-threatening bleeding, in whom very good efficacy in terms of clinical haemostasis was shown, and those referred for urgent surgery, in whom excellent efficacy around the time of surgery was demonstrated [36].

There is a concern that a person reversed from an anticoagulant might suffer from thrombotic complications. In the RE-VERSE AD trial 35 thrombotic events occurred in 31 of almost 500 patients at 90 days. Restart time varied, with a median time of 4.1 days in patients with life-threatening bleeding compared to a much shorter time of 1.4 days in those requiring urgent surgery [36]. Although the half-lives of dabigatran and idarucizumab are prolonged in patients with renal impairment, the adjustment of timing of re-initiation of dabigatran is not necessary. Almost two-thirds of patients had not had their anticoagulants restarted at the time of their thrombotic event. Thus, another key take-home message is that reversed patients must be started back on anticoagulants if they do not have a very high risk of bleeding.

\section{Andexanet alfa}

Andexanet alfa is a very specific reversal agent, which binds with high affinity not only to direct FXa inhibitors but also to low-molecular-weight heparins and fondaparinux, indirect FXa inhibitors [37]. Andexanet alfa is a modified human recombinant FXa decoy protein that lacks catalytic activity following replacement of an active-site serine with alanine and with removal of the membrane-binding domain, which precludes this protein from participating in the formation of the prothrombinase complex [37, 38].
In vitro andexanet alfa has been shown to correct increased anti-FXa activity caused by all four DOACs acting as FXa inhibitors, namely: rivaroxaban, apixaban, edoxaban, and betrixaban [38, 39]. Moreover, in animal bleeding models andexanet alfa has been demonstrated to decrease blood loss and restore haemostasis [40-42]. In phase II studies, andexanet demonstrated a rapid, dose-dependent reversal of anticoagulant effects (anti-FXa activity, unbound FXa concentrations, restoration of thrombin potential) in healthy volunteers who received apixaban, rivaroxaban, or enoxaparin [39, 43-45]. Because of its pharmacodynamic half-life of $1 \mathrm{~h}$, andexanet has been evaluated both as a bolus, and as a bolus followed by an infusion, with anti-FXa activity returning to placebo levels within $2 \mathrm{~h}$ of completion of dosing.

Results of two randomised, double-blind, placebo-controlled trials (Andexanet Alfa, a Novel Antidote to the Anticoagulation Effects of FXA Inhibitors [ANNEXA] trials) performed in healthy volunteers aged 50 to 75 years, who received apixaban (ANNEXA-A) and rivaroxaban (ANNEXA-R) were published [37]. Based on the phase II studies, a higher dose of andexanet was used for rivaroxaban than for apixaban because of higher plasma concentrations and a larger volume of distribution. For ANNEXA-A with apixaban, andexanet was given as a $400-\mathrm{mg}$ intravenous bolus $(30 \mathrm{mg} / \mathrm{min})$ in part one and a 400-mg bolus followed by a continuous infusion of $4 \mathrm{mg} / \mathrm{min}$ for $120 \mathrm{~min}$ (480 mg total) in part two. Corresponding doses in the ANNEXA-R with rivaroxaban were an 800-mg bolus and an 800-mg bolus followed by an infusion of $8 \mathrm{mg} / \mathrm{min}$ for $120 \mathrm{~min}$ (960 mg total) in parts one and two, respectively. The primary endpoint for the ANNEXA-A and ANNEXA-R studies was the maximum percentage change in anti-FXa activity. Anti-FXa activity was rapidly (within 2-5 min) reduced by $92 \%$ to $94 \%$ with the andexanet bolus and a reduction of $20 \%$ was observed in the placebo group. Following a dose of andexanet there is a fall of anti-Xa activity followed by a slow return of the anticoagulant effect of FXa inhibitor over time. The reversal of anti-FXa activity persists for $120 \mathrm{~min}$ with a slow increase as early as after 15 min since the end of administration of this agent. After a bolus of andexanet followed by an infusion, persistent inhibition of FXa is achieved, as long as the infusion is continued.

Of note, andexanet alfa has a good safety profile without thromboembolic or other serious adverse events, including no evidence of the generation of neutralising antibodies against this agent or FX or FXa. Transient increases in markers of blood coagulation activation reported during the ANNEXA-A and ANNEXA-R trials (namely D-dimer and prothrombin fragments 1.2) in study participants have uncertain clinical relevance.

The ANNEXA-4 phase IIIb to IV study assessed the efficacy and safety of andexanet alfa in patients treated with FXa inhibitors with acute major bleeding, but not in those anticoagulated subjects who require emergency or urgent procedures, which is in contrast to the REVERSE-AD trial 
$[36,46]$. The final results of this study should be reported in the near future.

At the present time, FXa inhibitors do not have reversal strategies in Europe or in Canada. On May 4 ${ }^{\text {th }}, 2018$ andexanet alfa was approved in the United States. However, there are some caveats regarding this reversal agent: (1) it will be available in very limited quantities for at least a year, and then it will be more widely available only in the United States; (2) the company estimates that it will cost about USD 25,000 for the lower dose and USD 50,000 for the higher dose, which effectively means that the vast majority of patients treated with rivaroxaban or apixaban will never have access to it, particularly outside the United States.

\section{Ciraparantag}

Ciraparantag is a small, water soluble, cationic synthetic molecule designed to specifically bind to unfractionated heparin, low-molecular-weight heparin, and DOACs, both thrombin and FXa inhibitors. This agent may be a universal antidote; however, it is in an early stage of development. The mechanism of its inhibitory effects involves noncovalent hydrogen bonding and charge-charge interactions. Ciraparantag has been demonstrated to normalise clotting time within 10 to $30 \mathrm{~min}$ of administration [47]. Ciraparantag has been investigated as an antidote for edoxaban $(60 \mathrm{mg})$ in a double-blind, placebo-controlled study [48]. A single intravenous dose of ciraparantag (100 to $300 \mathrm{mg}$ ) reversed anticoagulant effects within $10 \mathrm{~min}$ and sustained for $24 \mathrm{~h}$ in 80 healthy subjects. When administered to healthy subjects, ciraparantag is safe and well tolerated with minor, non-dose-limiting adverse events such as periorbital and facial flushing and cool sensation [48].

\section{NON-SPECIFIC REVERSAL STRATEGIES}

The available factor Xa inhibitor reversal strategies rely on non-specific strategies of unknown effectiveness. Prothrombin complex concentrates (PCCs) are widely used in those strategies but with no evidence of efficacy.

A prospective multicentre observational study, or a large case series, published in July 2017, described how physicians actually deal with bleeding on DOACs in the real world [49]. It demonstrated that reversal strategies are inconsistent with large variability in practice. Bleeds occurred in patients at an average age of almost 82 years. Looking at 460 bleeds that occurred in patients on DOACs, the authors reported that almost $20 \%$ of those patients received vitamin K, which is useless in such clinical situations. It has no possibility of having any effect but was given probably because many of these patients had a prolonged international normalised ratio (INR) due to rivaroxaban.

Tranexamic acid, an antifibrinolytic agent effective in trauma or postpartum haemorrhages, acts as a lysine analogue that impairs plasminogen activation on fibrin. In patients on DOACs its efficacy is uncertain; however, it might be used.
Fresh frozen plasma is ineffective in patients bleeding on DOACs but was used in about $10 \%$ of patients reported by $\mathrm{Xu}$ et al. [49]. Fresh frozen plasma may be used as a plasma volume expander in patients following transfusions, but its shortcomings are numerous and involve factors limiting its effectiveness, and it has a higher risk of transfusion reactions and acute heart failure, especially in the elderly, due to an increased volume and oncotic load [50-53].

Protrombin complex concentrates are plasma-derived products that contain three (factors II, IX, and X) or four (addition of factor VII) clotting factors in addition to variable amounts of heparin and the natural coagulation inhibitors, protein $\mathrm{C}$ and protein $\mathrm{S}$, which are used, among others, to reverse anticoagulant effects of VKA in severely bleeding patients. Activated PCC (aPCC), known as factor VIII inhibitor bypassing activity, contains activated factor VII along with mainly nonactivated factors II, IX, and X. Animal studies have demonstrated that PCCs have variable ability to normalise anticoagulation parameters and to prevent or attenuate bleeding across the DOACs [53-60]. Three randomised, placebo-controlled studies have been performed in 12 to 93 healthy volunteers who received DOACs. They demonstrated that PCCs can reverse the anticoagulant effect of rivaroxaban and edoxaban with complete reversal with $50 \mathrm{U} / \mathrm{kg}$ and partial reversal with $25 \mathrm{U} / \mathrm{kg}$, while no similar effect (no changes in TT, APTT, endogenous thrombin generation lag phase, and ecarin clotting time) was observed in subjects on dabigatran [61-64]. In vitro studies in healthy volunteers demonstrated that aPCCs added to plasma containing DOACs have a more potent effect on coagulation parameters than PCCs alone [65, 66]. If PCC or aPCC is selected to treat a patient with major or life-threatening DOAC-associated bleed, acknowledging the lack of evidence for this intervention, a dose of $50 \mathrm{U} / \mathrm{kg}$ of PCC or aPCC is recommended.

Another therapeutic option in bleeding patients on DOACs is recombinant activated factor VII (rFVIla, Novoseven). A few in vitro and ex vivo studies demonstrating variable efficacy of $\mathrm{rFVIla}$ to reverse coagulation parameters attributable to DOACs [65, 66-73] have been published. There have been a few case reports of patients receiving this agent due to life-threatening bleeding, although there have been no clinical trials investigating this strategy. Based on limited experience, a dose of $90 \mathrm{U} / \mathrm{kg}$ used in patients with acquired haemophilia A has been proposed to limit the most severe bleeding on DOACs [49].

Interestingly, reasonable non-specific strategies that might be used in emergency situations including PCC, aPCC, or rFVIla were all used in fewer than $20 \%$ of patients with serious bleeding on DOACs in the real-life study by Xu et al. [49].

Experts suggest that hospitals should adopt anticoagulation reversal protocols developed by a multidisciplinary team involving intensivists, cardiologists, haematologists, surgeons, gastroenterologists, neurologists, and others. Examples of 
such protocols are available for clinicians, but they should be adapted to local circumstances [74]. By standardising approaches to care and minimising the risk of missing key interventions, such studies are likely to improve care for patients with bleeding.

\section{EXAMPLES OF DECISION-MAKING REGARDING BLEEDING PATIENTS ON DOACS \\ Case 1}

A 79-year-old man with permanent $\mathrm{AF}$ receiving dabigatran $150 \mathrm{mg}$ twice a day reported to the emergency department presenting with new hemiparesis and aphasia. Computed tomography revealed subdural haemorrhage. His blood tests were as follows: INR of 1.1, APTT of $35 \mathrm{~s}$, and TT of $135 \mathrm{~s}$ (reference range below $30 \mathrm{~s}$ ). The question is whether he should receive some form of reversal agent.

The decision was not to administer idarucizumab. The thrombin time of $135 \mathrm{~s}$ indicates that he still has some dabigatran in circulating blood, but the thrombin time goes up very quickly with dabigatran, so the level of 135 means he probably does not have very much of the drug in the system. And by the time he actually got the reversal agent administered he would probably have no dabigatran left.

\section{Case 2}

A 71-year-old man presented to the emergency department at 8:00 p.m. on a Saturday night with abdominal pain and hypotension. Imaging revealed a ruptured abdominal aortic aneurysm. He had non-valvular AF, arterial hypertension, dyslipidaemia, and a history of ischaemic stroke one year ago. He was taking apixaban $5 \mathrm{mg}$ twice a day. His last dose of apixaban had been taken approximately $12 \mathrm{~h}$ previously. The surgeon called the lab and asked for proof that there was no anticoagulant effect present. The laboratory examination was as follows: haemoglobin $10.2 \mathrm{~g} / \mathrm{dL}$, platelet count 292,000/ $\mathrm{LL}$. The prothrombin time, INR, and APTT were normal. The anti-Xa level was sent, but will not be available in a realistic time-frame. The question is whether this person has a discernible anticoagulant effect and if we should do something to intervene to reduce the risk of bleeding when he goes for surgery. An immediate decision is needed; vascular surgeon recommends emergent open repair; $2 \mathrm{~h}$ is too long to wait. What strategy should be recommended?

One might think that the normal results of the coagulation tests indicate that the person does not have an anticoagulant effect; however, apixaban does not produce any effect on the most commonly available coagulation tests. Therefore, if a person is taking apixaban, the INR, prothrombin time, APTT, and thrombin time are all useless. If this person receiving apixaban has a ruptured abdominal aortic aneurysm, the surgery should be performed and the surgeon should be advised that the patient may have increased risk of bleeding. Prothrombin complex concentrates are widely used to treat bleeding in patients taking DOACs, and they might be considered if the person bleeds excessively in the operating room. In all likelihood the patient is not going to have abnormal bleeding because the apixaban was taken $12 \mathrm{~h}$ earlier.

\section{SUMMARY}

Reversal strategies in patients receiving DOACs depend on the anticoagulant involved, the location and severity of the bleeding, and/or the urgency of the invasive procedure. The available specific reversal agent for dabigatran, idarucizumab, is used infrequently for the reversal of DOACs, without increasing the underlying risk of thrombosis. Andexanet alfa to reverse FXa inhibitors has been approved by the FDA recently. Evidence supporting non-specific reversal therapies including PCC, aPCC, or recombinant factor VIla is still limited in terms of clinical outcome data. Administration of PCC or aPCC may be considered in addition to supportive measures for patients with severe or life-threatening bleeding.

Most importantly, the best way to treat a bleed related to a DOAC is to prevent it by using the right drug at the right dose in the right patient and by withdrawing anticoagulation in patients without an indication for such therapy.

This review was based on a lecture at the $4^{\text {th }}$ McMaster International Review Course in Internal Medicine in Krakow, Poland, on $12^{\text {th }}$ May 2018.

Conflict of interest: Mark Crowther has received consulting fees and speaker honoraria from Bayer, Boehringer-Ingelheim, Bristol Myers Squibb, Daiichi-Sankyo, Janssen, Portola Pharmaceuticals, and Pfizer. Adam Cuker has received consulting fees from Genzyme, Kedrion, and Synergy and has received research support from Alexion, Bayer, Novo-Nordisk, Pfizer, Sanofi, Shire, and Spark.

\section{References}

1. Barnes GD, Ageno W, Ansell J, et al. Recommendation on the nomenclature for oral anticoagulants: communication from the SSC of the ISTH. J Thromb Haemost. 2015; 13(6): 1154-1156, doi: 10.1111/jth.12969, indexed in Pubmed: 25880598.

2. Connolly S, Ezekowitz M, Yusuf S, et al. Dabigatran versus warfarin in patients with atrial fibrillation. N Engl J Med. 2009; 361(12): 1139-1151, doi: 10.1056/nejmoa0905561.

3. Connolly SJ, Ezekowitz MD, Yusuf S, et al. Randomized Evaluation of Long-Term Anticoagulation Therapy Investigators. Newly identified events in the RE-LY trial. N Engl J Med. 2010; 363(19): 1875-1876, doi: 10.1056/NEJMc1007378, indexed in Pubmed: 21047252.

4. Patel MR, Mahaffey KW, Garg J, et al. ROCKET AF Investigators. Rivaroxaban versus warfarin in nonvalvular atrial fibrillation. N Engl J Med. 2011; 365(10): 883-891, doi: 10.1056/NEJMoa1009638, indexed in Pubmed: 21830957.

5. Granger C, Alexander J, McMurray J, et al. Apixaban versus Warfarin in Patients with Atrial Fibrillation. N Engl J Med. 2011; 365(11): 981-992, doi: 10.1056/nejmoa1107039.

6. Giugliano R, Ruff C, Braunwald E, et al. ENGAGE AF-TIMI 48 Investigators. Edoxaban versus warfarin in patients with 
atrial fibrillation. N Engl J Med. 2013; 369(22): 2093-2104, doi: 10.1056/nejmoa1310907.

7. Agnelli G, Buller HR, Cohen A, et al. AMPLIFY Investigators. Oral apixaban for the treatment of acute venous thromboembolism. N Engl J Med. 2013; 369(9): 799-808, doi: 10.1056/NEJMoa1302507, indexed in Pubmed: 23808982.

8. Büller HR, Décousus H, Grosso MA, et al. Hokusai-VTE Investigators. Edoxaban versus warfarin for the treatment of symptomatic venous thromboembolism. N Engl J Med. 2013; 369(15): 1406-1415, doi: 10.1056/NEJMoa1306638, indexed in Pubmed: 23991658.

9. Prins MH, Lensing AWa, Bauersachs R, et al. EINSTEIN Investigators. Oral rivaroxaban versus standard therapy for the treatment of symptomatic venous thromboembolism: a pooled analysis of the EINSTEIN-DVT and PE randomized studies. Thromb J. 2013; 11(1): 21, doi: 10.1186/1477-9560-11-21, indexed in Pubmed: 24053656.

10. Schulman S, Kakkar AK, Goldhaber SZ, et al. RE-COVER II Trial Investigators. Treatment of acute venous thromboembolism with dabigatran or warfarin and pooled analysis. Circulation. 2014; 129(7): 764-772, doi: 10.1161/CIRCULATIONAHA.113.004450, indexed in Pubmed: 24344086.

11. Pengo V, Denas G, Zoppellaro G, et al. Rivaroxaban vs warfarin in high-risk patients with antiphospholipid syndrome. Blood. 2018; 132(13): 1365-1371, doi: 10.1182/blood-2018-04-848333, indexed in Pubmed: 30002145.

12. Ruff CT, Giugliano RP, Braunwald E, et al. Comparison of the efficacy and safety of new oral anticoagulants with warfarin in patients with atrial fibrillation: a meta-analysis of randomised trials. Lancet. 2014; 383(9921): 955-962, doi: 10.1016/S01406736(13)62343-0, indexed in Pubmed: 24315724.

13. van der Hulle T, Kooiman J, den Exter PL, et al. Effectiveness and safety of novel oral anticoagulants as compared with vitamin K antagonists in the treatment of acute symptomatic venous thromboembolism: a systematic review and meta-analysis. J Thromb Haemost. 2014; 12(3): 320-328, doi: 10.1111/jth.12485, indexed in Pubmed: 24330006.

14. Beyer-Westendorf J, Forster K, Pannach S, et al. Rates, management, and outcome of rivaroxaban bleeding in daily care: results from the Dresden NOAC registry. Blood. 2014; 124(6): 955-962, doi: 10.1182/blood-2014-03-563577.

15. Ebertz F, Förster K, Gelbricht V, et al. Effectiveness and safety of dabigatran therapy in daily-care patients with atrial fibrillation. Thromb Haemost. 2015; 113(6): 1247-1257, doi: 10.1160/th1411-0954.

16. Graham DJ, Reichman ME, Wernecke M, et al. Cardiovascular, bleeding, and mortality risks in elderly Medicare patients treated with dabigatran or warfarin for nonvalvular atrial fibrillation. Circulation. 2015; 131(2): 157-164, doi: 10.1161/CIRCULATIONAHA.114.012061, indexed in Pubmed: 25359164

17. Larsen TB, Rasmussen LH, Skjøth F, et al. Efficacy and safety of dabigatran etexilate and warfarin in "real-world" patients with atrial fibrillation: a prospective nationwide cohort study. J Am Coll Cardiol. 2013; 61(22): 2264-2273, doi: 10.1016/j. jacc.2013.03.020, indexed in Pubmed: 23562920.

18. Larsen TB, Gorst-Rasmussen A, Rasmussen LH, et al. Bleeding events among new starters and switchers to dabigatran compared with warfarin in atrial fibrillation. Am J Med. 2014; 127(7): 650-656.e5, doi: 10.1016/j.amjmed.2014.01.031, indexed in Pubmed: 24530792.

19. Chai-Adisaksopha $\mathrm{C}$, Crowther M, Isayama $\mathrm{T}$, et al. The impact of bleeding complications in patients receiving target-specific oral anticoagulants: a systematic review and meta-analysis. Blood. 2014; 124(15): 2450-2458, doi: 10.1182/blood-2014-07-590323, indexed in Pubmed: 25150296.

20. Linkins LA, Choi PT, Douketis JD. Clinical impact of bleeding in patients taking oral anticoagulant therapy for venous throm- boembolism: a meta-analysis. Ann Intern Med. 2003; 139(11): 893-900, indexed in Pubmed: 14644891.

21. Fang MC, Go AS, Chang Y, et al. Death and disability from warfarin-associated intracranial and extracranial hemorrhages. Am JMed. 2007; 120(8): 700-705, doi: 10.1016/j.amjmed.2006.07.034, indexed in Pubmed: 17679129.

22. Holster IL, Valkhoff VE, Kuipers EJ, et al. New oral anticoagulants increase risk for gastrointestinal bleeding: a systematic review and meta-analysis. Gastroenterology. 2013; 145(1): 105-112.e15, doi: 10.1053/j.gastro.2013.02.041, indexed in Pubmed: 23470618.

23. Desai J, Kolb JM, Weitz JI, et al. Gastrointestinal bleeding with the new oral anticoagulants - defining the issues and the management strategies. Thromb Haemost. 2013; 110(2): 205-212, doi: 10.1160/TH13-02-0150, indexed in Pubmed: 23702623.

24. Kirchhof P, Benussi S, Kotecha D, et al. [2016 ESC Guidelines for the management of atrial fibrillation developed in collaboration with EACTS]. Kardiol Pol. 2016; 74(12): 1359-1469.

25. Valgimigli M, Bueno H, Byrne RA, et al. [2017 ESC focused update on dual antiplatelet therapy in coronary artery disease developed in collaboration with EACTS]. Kardiol Pol. 2017; 75(12): 1217-1299.

26. Schiele F, van Ryn J, Canada K, et al. A specific antidote for dabigatran: functional and structural characterization. Blood. 2013; 121(18): 3554-3562, doi: 10.1182/blood-2012-11-468207, indexed in Pubmed: 23476049.

27. Eikelboom JW, Quinlan DJ, van Ryn J, et al. Idarucizumab: The Antidote for Reversal of Dabigatran. Circulation. 2015; 132(25): 2412-2422, doi: 10.1161/CIRCULATIONAHA.115.019628, indexed in Pubmed: 26700008.

28. Glund S, Moschetti V, Norris S, et al. A randomised study in healthy volunteers to investigate the safety, tolerability and pharmacokinetics of idarucizumab, a specific antidote to dabigatran. Thromb Haemost. 2015; 113(5): 943-951, doi: 10.1160/TH14-121080, indexed in Pubmed: 25789661.

29. Meibohm B, Zhou H. Characterizing the impact of renal impairment on the clinical pharmacology of biologics. J Clin Pharmacol. 2012; 52(1 Suppl): 54S-62S, doi: 10.1177/0091270011413894, indexed in Pubmed: 22232754.

30. Glund S, Stangier J, Schmohl M, et al. Idarucizumab, a specific antidote for dabigatran: immediate, complete and sustained reversal of dabigatran induced anticoagulation in elderly and renally impaired subjects. Blood. 2014; 124(13): 344-353.

31. Glund S, Stangier J, Schmohl M, et al. Safety, tolerability, and efficacy of idarucizumab for the reversal of the anticoagulant effect of dabigatran in healthy male volunteers: a randomised, placebo-controlled, double-blind phase 1 trial. Lancet. 2015; 386(9994): 680-690, doi: 10.1016/S0140-6736(15)60732-2, indexed in Pubmed: 26088268.

32. Pruszczyk P, Tomaszuk-Kazberuk A, Słowik A, et al. Management of bleeding or urgent interventions in patients treated with direct oral anticoagulants: 2017 recommendations for Poland. Pol Arch Intern Med. 2017; 127(5): 343-351, doi: 10.20452/pamw.3995, indexed in Pubmed: 28400546.

33. Mazur P, Darocha T, Filip G, et al. Idarucizumab for dabigatran reversal in patients with atrial fibrillation undergoing emergency surgery for acute aortic syndrome. Pol Arch Med Wewn. 2016; 126(7-8): 579-581, doi: 10.20452/pamw.3470, indexed in Pubmed: 27452811

34. Tomaszuk-Kazberuk A, Łopatowska P, Młodawska E, et al. Successful use of idarucizumab as a reversal agent for dabigatran in a patient with acute dissected aortic aneurysm. Pol Arch Intern Med. 2017; 127(1): 68-70, doi: 10.20452/pamw.3918, indexed in Pubmed: 28146465.

35. Pollack C, Reilly P, Eikelboom J, et al. Idarucizumab for dabigatran reversal. N Engl J Med. 2015; 373(6): 511-520, doi: 10.1056/nejmoa1502000. 
36. Pollack CV, Reilly PA, van Ryn J, et al. Idarucizumab for dabigatran reversal - full cohort analysis. N Engl J Med. 2017; 377(5): 431-441, doi: 10.1056/NEJMoa1707278, indexed in Pubmed: 28693366.

37. Siegal DM, Curnutte JT, Connolly SJ, et al. Andexanet Alfa for the Reversal of Factor Xa Inhibitor Activity. N Engl J Med. 2015; 373(25): 2413-2424, doi: 10.1056/NEJMoa1510991, indexed in Pubmed: 26559317.

38. Lu G, DeGuzman FR, Hollenbach SJ, et al. A specific antidote for reversal of anticoagulation by direct and indirect inhibitors of coagulation factor Xa. Nat Med. 2013; 19(4): 446-451, doi: 10.1038/nm.3102, indexed in Pubmed: 23455714.

39. Crowther M, Levy G, Lu G, et al. A phase 2 randomized, double-blind, placebo-controlled trial demonstrating reversal of edoxaban induced anticoagulation in healthy subjects by andexana (PRT064445), a universal antidote for factor Xa (fXa) inhibitors. Blood. 2014; 124(1): 4269.

40. Hashizume M, Tan SL, Takano J, et al. Tocilizumab, a humanized anti-IL-6R antibody, as an emerging therapeutic option for rheumatoid arthritis: molecular and cellular mechanistic insights. Int Rev Immunol. 2015; 34(3): 265-279, doi: 10.3109/08830185.2014. 938325, indexed in Pubmed: 25099958.

41. Zhang LJ, Lu GM. Takayasu's arteritis involving the pulmonary arteries: evaluation by quantitative dual-energy computed tomographic pulmonary angiography. Eur Heart J. 2012; 33(7): 928, doi: 10.1093/eurheartj/ehr335, indexed in Pubmed: 21896563.

42. Lu G, Deguzman F, Hollenbach S, et al. Reversal of low molecular weight heparin and fondaparinux by a recombinant antidote (r-Antidote, PRT064445). Circulation. 2010; 122(1): 12420.

43. Crowther M, Lu G, Conley P, et al. Reversal of factor Xa inhibitors induced anticoagulation in healthy subjects by andexanet alfa. Crit Care Med. 2014; 42(1): A1469.

44. Crowther M, Mathur V, Kitt M, et al. A phase 2 randomized, double-blind, placebo-controlled trial demonstrating reversal of rivaroxaban-induced anticoagulation in healthy subjects by andexanet alfa (PRT064445), an antidote for FXa inhibitors. Blood. 2014; 124: 4269

45. Crowther M, Kitt M, Lorenz T, et al. A phase 2 randomized, double-blind, placebo-controlled trial of PRT064445, a novel, universal antidote for direct and indirect factor Xa inhibitors. J Thromb Haemost. 2013; 11(Suppl 2): 30.

46. Ruff CT, Giugliano RP, Antman EM. Management of bleeding with non-vitamin $\mathrm{K}$ antagonist oral anticoagulants in the era of specific reversal agents. Circulation. 2016; 134(3): 248-261, doi: 10.1161/CIRCULATIONAHA.116.021831, indexed in Pubmed: 27436881.

47. Ansell JE, Bakhru SH, Laulicht BE, et al. Use of PER977 to reverse the anticoagulant effect of edoxaban. N Engl J Med. 2014 371(22): 2141-2142, doi: 10.1056/NEJMc1411800, indexed in Pubmed: 25371966.

48. Ansell JE, Bakhru SH, Laulicht BE, et al. Single-dose ciraparantag safely and completely reverses anticoagulant effects of edoxaban. Thromb Haemost. 2017; 117(2): 238-245, doi: 10.1160/TH16-030224, indexed in Pubmed: 27853809.

49. Xu Y, Schulman S, Dowlatshahi D, et al. Direct oral anticoagulant- or warfarin-related major bleeding: characteristics, reversal strategies, and outcomes from a multicenter observational study. Chest. 2017; 152(1): 81-91, doi: 10.1016/j.chest.2017.02.009, indexed in Pubmed: 28219635.

50. Sarode R, Milling TJ, Refaai MA, et al. Efficacy and safety of a 4 -factor prothrombin complex concentrate in patients on vitamin K antagonists presenting with major bleeding: a randomized, plasma-controlled, phase IIIb study. Circulation. 2013; 128(11): 1234-1243, doi: 10.1161/CIRCULATIONAHA.113.002283, indexed in Pubmed: 23935011.

51. Heidbuchel H, Verhamme P, Alings M, et al. Updated European Heart Rhythm Association Practical Guide on the use of non-vitamin K antagonist anticoagulants in patients with non-valvular atrial fibrillation. Europace. 2015; 17(10): 1467-1507, doi: 10.1093/europace/euv309, indexed in Pubmed: 26324838.

52. Kovacs RJ, Flaker GC, Saxonhouse SJ, et al. Practical management of anticoagulation in patients with atrial fibrillation. J Am Coll Cardiol. 2015; 65(13): 1340-1360, doi: 10.1016/j. jacc.2015.01.049, indexed in Pubmed: 25835447.

53. Weitz JI, Pollack CV. Practical management of bleeding in patients receiving non-vitamin $\mathrm{K}$ antagonist oral anticoagulants. Thromb Haemost. 2015; 114(6): 1113-1126, doi: 10.1160/TH15-03-0222, indexed in Pubmed: 26155974.

54. Pragst I, Zeitler SH, Doerr B, et al. Reversal of dabigatran anticoagulation by prothrombin complex concentrate (Beriplex $\mathrm{P} / \mathrm{N}$ ) in a rabbit model. J Thromb Haemost. 2012; 10(9): 1841-1848, doi: 10.1111/j.1538-7836.2012.04859.x, indexed in Pubmed: 22812619.

55. Godier A, Miclot A, Le Bonniec B, et al. Evaluation of prothrombin complex concentrate and recombinant activated factor VII to reverse rivaroxaban in a rabbit model. Anesthesiology. 2012; 116(1): 94-102, doi: 10.1097/ALN.0b013e318238c036, indexed in Pubmed: 22042412.

56. Lambourne MD, Eltringham-Smith LJ, Gataiance S, et al. Prothrombin complex concentrates reduce blood loss in murine coagulopathy induced by warfarin, but not in that induced by dabigatran etexilate. J Thromb Haemost. 2012; 10(9): 1830-1840, doi: 10.1 111/j.1538-7836.2012.04863.x, indexed in Pubmed: 22817470.

57. Perzborn E, Gruber A, Tinel H, et al. Reversal of rivaroxaban anticoagulation by haemostatic agents in rats and primates. Thromb Haemost. 2013; 110(1): 162-172, doi: 10.1160/TH12-12-0907, indexed in Pubmed: 23636219.

58. Martin AC, Le Bonniec B, Fischer AM, et al. Evaluation of recombinant activated factor VII, prothrombin complex concentrate, and fibrinogen concentrate to reverse apixaban in a rabbit model of bleeding and thrombosis. Int J Cardiol. 2013; 168(4): 4228-4233, doi: 10.1016/j.ijcard.2013.07.152, indexed in Pubmed: 23928345.

59. Zhou W, Zorn M, Nawroth P, et al. Hemostatic therapy in experimental intracerebral hemorrhage associated with rivaroxaban. Stroke. 2013; 44(3): 771-778, doi: 10.1161/STROKEAHA.112.675231, indexed in Pubmed: 23339956.

60. Honickel M, Treutler S, van Ryn J, et al. Reversal of dabigatran anticoagulation ex vivo: Porcine study comparing prothrombin complex concentrates and idarucizumab. Thromb Haemost. 2015; 113(4): 728-740, doi: 10.1160/TH14-08-0712, indexed in Pubmed: 25567155.

61. Aronis KN, Hylek EM. Who, when, and how to reverse non-vitamin K oral anticoagulants. J Thromb Thrombolysis. 2016; 41(2): 253-272, doi: 10.1007/s11239-015-1297-0, indexed in Pubmed: 26627486 .

62. Eerenberg ES, Kamphuisen PW, Sijpkens MK, et al. Reversal of rivaroxaban and dabigatran by prothrombin complex concentrate: a randomized, placebo-controlled, crossover study in healthy subjects. Circulation. 2011; 124(14): 1573-1579, doi: 10.1161/CIRCULATIONAHA.111.029017, indexed in Pubmed: 21900088

63. Levi M, Moore KT, Castillejos CF, et al. Comparison of three-factor and four-factor prothrombin complex concentrates regarding reversal of the anticoagulant effects of rivaroxaban in healthy volunteers. J Thromb Haemost. 2014; 12(9): 1428-1436, doi: 10.1111/jth.12599, indexed in Pubmed: 24811969.

64. Zahir H, Brown KS, Vandell AG, et al. Edoxaban effects on bleeding following punch biopsy and reversal by a 4 -factor prothrombin complex concentrate. Circulation. 2015; 131(1): 82-90, doi: 10.1161/CIRCULATIONAHA.114.013445, indexed in Pubmed: 25403645.

65. Marlu R, Hodaj E, Paris A, et al. Effect of non-specific reversal agents on anticoagulant activity of dabigatran and rivaroxaban: a randomised crossover ex vivo study in 
healthy volunteers. Thromb Haemost. 2012; 108(2): 217-224, doi: 10.1160/TH12-03-0179, indexed in Pubmed: 22627883.

66. Escolar G, Fernandez-Gallego V, Arellano-Rodrigo E, et al. Reversal of apixaban induced alterations in hemostasis by different coagulation factor concentrates: significance of studies in vitro with circulating human blood. PLoS One. 2013; 8(11): e78696, doi: 10.1371/journal.pone.0078696, indexed in Pubmed: 24244342.

67. Fukuda T, Honda Y, Kamisato C, et al. Reversal of anticoagulant effects of edoxaban, an oral, direct factor Xa inhibitor, with haemostatic agents. Thromb Haemost. 2012; 107(2): 253-259, doi: 10.1160/TH11-09-0668, indexed in Pubmed: 22186946.

68. Herrmann R, Thom J, Wood A, et al. Thrombin generation using the calibrated automated thrombinoscope to assess reversibility of dabigatran and rivaroxaban. Thromb Haemost. 2014; 111(5): 989-995, doi: 10.1160/TH13-07-0607, indexed in Pubmed: 24352511.

69. Körber MK, Langer E, Ziemer S, et al. Measurement and reversal of prophylactic and therapeutic peak levels of rivaroxaban: an in vitro study. Clin Appl Thromb Hemost. 2014; 20(7): 735-740, doi: 10.1177/1076029613494468, indexed in Pubmed: 23832064.

70. Perzborn E, Heitmeier S, Laux V, et al. Reversal of rivaroxaban-induced anticoagulation with prothrombin complex concentrate, activated prothrombin complex concentrate and recombinant activated factor VII in vitro. Thromb Res. 2014; 133(4): 671-681, doi: 10.1016/j.thromres.2014.01.017, indexed in Pubmed: 24529498.

71. Escolar G, Arellano-Rodrigo E, Lopez-Vilchez I, et al. Reversal of rivaroxaban-induced alterations on hemostasis by different coagulation factor concentrates - in vitro studies with steady and circulating human blood. Circ J. 2015; 79(2): 331-338, doi: 10.1253/circj.CJ-14-0909, indexed in Pubmed: 25482382.

72. Halim AB, Samama MM, Mendell J. Ex vivo reversal of the anticoagulant effects of edoxaban. Thromb Res. 2014; 134(4):
909-913, doi: 10.1016/j.thromres.2014.07.036, indexed in Pubmed: 25179520.

73. Siegal DM. Managing target-specific oral anticoagulant associated bleeding including an update on pharmacological reversal agents. J Thromb Thrombolysis. 2015; 39(3): 395-402, doi: 10.1007/s11239-015-1167-9, indexed in Pubmed: 25586208.

74. Raval AN, Cigarroa JE, Chung MK, et al. Management of patients on non-vitamin K antagonist oral anticoagulants in the acute care and periprocedural setting: a scientific statement from the American Heart Association. Circulation. 2017; 135(10): e604-e633, doi: 10.1161/CIR.0000000000000477, indexed in Pubmed: 28167634.

75. Schulman S, Kearon C, Kakkar AK, et al. RE-COVER Study Group. Dabigatran versus warfarin in the treatment of acute venous thromboembolism. N Engl J Med. 2009; 361(24): 2342-2352, doi: 10.1056/NEJMoa0906598, indexed in Pubmed: 19966341.

76. Schulman S, Kearon C, Kakkar AK, et al. RE-MEDY Trial Investigators, RE-SONATE Trial Investigators. Extended use of dabigatran, warfarin, or placebo in venous thromboembolism. N Engl J Med. 2013; 368(8): 709-718, doi: 10.1056/NEJMoa1113697, indexed in Pubmed: 23425163.

77. Büller HR, Prins MH, Lensin AWA, et al. EINSTEIN-PE Investigators. Oral rivaroxaban for the treatment of symptomatic pulmonary embolism. N Engl J Med. 2012; 366(14): 1287-1297, doi: 10.1056/NEJMoa1113572, indexed in Pubmed: 22449293.

78. Hori M, Matsumoto M, Tanahashi N, et al. J-ROCKET AF study investigators. Rivaroxaban vs. warfarin in Japanese patients with atrial fibrillation - the J-ROCKET AF study. Circ J. 2012; 76(9): 2104-2111, indexed in Pubmed: 22664783.

79. Bauersachs R, Berkowitz SD, Brenner B, et al. EINSTEIN Investigators. Oral rivaroxaban for symptomatic venous thromboembolism. N Engl J Med. 2010; 363(26): 2499-2510, doi: 10.1056/NEJMoa1007903, indexed in Pubmed: 21128814.

Cite this article as: Crowther M, Cuker A. How can we reverse bleeding in patients on direct oral anticoagulants? Kardiol Pol. 2019; 77(1): 3-11, doi: 10.5603/KP.a2018.0197. 